\title{
AN ANALYSIS OF LESSON PLAN IMPLEMENTATION THROUGH ZOOM IN TEACHING WRITING BASED ON INTERNATIONAL PRIMARY CURRICULUM IN SUNRISE SCHOOL BALI
}

\author{
K.T.D. Pradipta ${ }^{1}$, D.K. Tantra ${ }^{2}$, D.P. Ramendra ${ }^{3}$ \\ ${ }^{123}$ English Language Education, Universitas Pendidikan Ganesha, Singaraja \\ e-mail: tiadwipradipta@gmail.com , komang.tantra@undiksha.ac.id, putu.ramendra@undiksha.ac.id
}

The present research studied teachers' ability and constraints in preparing and implementing the lesson plan for writing through Zoom during the pandemic Covid-19 in the Year 6 Primary School Denpasar. The research was designed using a Mixed Method. Data were collected by means of five instruments and the obtained data on the five variables were analyzed descriptively to measure the arithmetic means, range, standard deviation, and variance. This study showed that the teachers' ability in preparing for lesson plan were categorized in high category. The teachers' ability in implementing the lesson plan were also categorized as high category. Some constraints were encountered by the teachers in preparing and implementing lesson plan for writing through Zoom. It is suggested that EFL students and teachers to be trained to improve the use of online learning as well as their literacy in information technology, especially the one related to EFL instruction online.

\section{Keywords: Lesson Plan; Writing; Zoom}

\section{INTRODUCTION}

Today's learning and teaching process seems to be more challenging since the pandemic situation forces the teachers work beyond their usual teaching activity as the world now facing the online teaching and learning based process (Barton, 2020). The challenge that might be occurred during learning in Covid-19 pandemic is about how to grade the students, prepare assignment for students and how to promote the learning if the teachers have instructional contraints such as lack of expertise, large course size and overloaded curriculum (Reynolds et al., 2020). Because of that, planning the lesson for teaching during Covid-19 pandemic necessary to continue teaching and learning without interruption (Ferri, Grifoni, \& Guzzo, 2020) in which the lesson plan can be adopted by the teacher from online educational resources or modify it into their own educational materials (Reimers, Schleicher, Saavedra, \& Tuominen, 2020). A lesson plan is one of the essential parts that may lead English teachers to gain the expected learning outcome. It is also defined as the plan of the learning activities for one or more meeting; it is developed from the syllabus to direct the students" learning activities to achieve the basic competence; every teacher is required to make a lesson plan completely and systematically in order that the learning taking place can be interactive, inspiring, fun, challenging, efficient, motivating students to actively participate in the learning and giving a space for students" work, creativity, and independence in accordance with their passion, talent and psychological and physical development(Sugianto, 2020). Based on Sugiyono's statement, it can be assumed that lesson plan should be organized to create learning success for the students, including students' creativity which can be done through writing

According to Reynolds et al. (2020), writing can be facilitated in online learning by engaging the students to give feedback and revision to help them improve their critical thinking skill and engage them to the complex ideas. Writing is an important skill in EFL as it includes the process of generating, organizing, and translating ideas into the writing form of text (Richard, 2019). From this point, it can be showed that in writing, learner need to understand words to be combined with one another in order to get a good sentence. Further, learners also need to avoid some grammatical errors which include words misspell and words misplacement that may impact the sentences meaning and also make misunderstanding between the readers. Moreover, it is indicated that before the learners 
doing the writing, there should be a concept in mind about what will be put on the paper. The concept is not only about the draft or master words point to be developed, but also how each point in each paragraph can be connected and can lead the reader into a good understanding as the writer meant from the beginning. These general points of views may indicate that writing process is not easy to be done; words choices, ideas, and also developing concepts are claimed to be the points to make good writing.

Hairston (1982) believes that writing is one of the difficult skills, since it takes process of connecting meaningful words in order to make good sentences, and from good sentences can be created relevant paragraphs. It can be stated that Hairston specifies that writing includes three main terms; words, sentences and paragraph. Those three things need to be connected one another in order to make good writing. When they are specified can be explained as follow: (1) Word. In writing process, the word choice is paramount since the whole other 2 aspects relay on this word. The correct words choice can build meaningful sentence and also good paragraph. Unfortunately, the word choice is more likely to be risky since not all the learners are able to choose good sentence in their writing. It is indicated that grammatical errors may affect words meaning and words' function in a sentence and also paragraph. As a solution, the learners need to master the words that they choose in their writing, then write or type the words as correct as possible with no misspell and also misplacement. (2) Sentence. The sentence can happen when some meaningful words are connected and create a meaning to support the idea or concept from the writer. The success of the writer to put words into sentence can be noticed from the meaning of the sentences and how one sentence and the others can explain the same concept and ideas which are getting bigger in term of development from the very first paragraph into the next ones. (3) The paragraph. As the correct meaningful words are combined into sentences, and connectedsupported sentences are involved to make a paragraph as supporting idea, then the whole paragraph in a writing can explain concept and idea from the writer, from paragraph one into the next ones which are getting bigger and complex in term of supporting ideas into the main idea or the title.

The theory from Hairston has the same understanding with a theory from Hodges (2017). Hodges also mentioned that make good writing must take some practices and also times with couple of topics and ideas to put on in order to connect the cognitive process and the communication in form of writing. The practice includes how to choose the words that may support the ideas as details, and also make the flowing ideas of the writer's idea become more interesting to be followed. Besides, the errors in choosing words (misspell and misplacement) also need to be considered as the terms to be practiced by carefully writing the words and typing the words after knowing the meaning of the words. Then, the other practices include the paragraph developing. Each paragraph needs to be developed by connecting each of them without losing the meaning of main idea from the beginning. Moreover, the paragraph needs to be bringing out the flowing ideas which lead the reader from the starting paragraph, middle paragraph and also the ending which ends and conclude the all ideas from the beginning.

Those three theories from Richard, Hairston and Hodges are now related into the current situation which the Pandemic, which is believed has affected the way of teaching and learning process to happen in almost all over the world, especially in Indonesia. There is new policy released by the Minister of Education in Indonesia regarding to the Pandemic in which all the learning process in all schools (include international school) need to be conducted through on-line learning platforms (Kemdikbud,2020). This policy is implemented based on the Circular Letter of the Indonesia Ministry of National Education and Culture Number 1 Year 2020 on Learning Freedom Policy. In short, it can be claimed that the writing learning process in which it was stated before by Hairston as a difficult process to do, then at this very moment is becoming even more difficult as the online learning process is chosen as the main way of teaching and learning process, especially in elementary school since in elementary school is emphasized on rhetorical moves and organization structure (Yinling, 2016). In relation to education system in Indonesia, it is important to learn writing for primary school because learning in primary school based on 2013 Curriculum is emphasized on thematicintegrative learning which involved several subjects under general theme which is expected 
for the students to acquire a range of knowledge which means students must be able to produce handwriting with correct spelling, punctuation and grammar (Sulfasyah, Bahri, \& Saleh, 2018).

The online class specified in writing was supported by some platforms, namely; Zoom, Google Meet, and zoom (Namaziandost \& Nasri,2019; Muhammed,2020). Then, like other online meeting platform, zoom is recognized as online meeting platform and webinar which enable the user to share content at the same time as the video conferencing. As it is currently claimed by bulletin of science and practice in 2020 that Zoom has features in which both teacher and learner can explore and assess the four skills by emphasizing on writing. Even though, the learning process is doing online, the teacher and learners still can do interactions through the video conferencing, even the learners can do their own writing practice at home through the screen sharing in which the learners can follow the instructions as the same as normal learning class at school. Further, it is also indicated that Zoom can provide the assessing/ evaluation process. Learners' task can be evaluated through screen sharing, and it can be noticed and watched by other learners as well as the same time. Then, with secure recording session feature in zoom it makes the learners can review the learning process that happened before by playing the recording file, it also means that in zoom the learners who still have some questions in mind when the online learning session is finished can learn by watching the record of the learning session (Zoom Video Communication, 2016). This is in line with Guzacheva (2020) who stated Zoom's features allow English teachers to explore and assess the four skills through rich interactions with medical students. In addition to screen sharing, Zoom motivates English teachers to annotate their shared screen, making lessons more interactive. English teachers can record their lessons to the Cloud or locally medical students can also record and turn recording on and off as many times as they like during a lesson, if the teacher enables this feature. Teachers can record lessons and watch them again to assess medical students' strengths and weaknesses and learners can selfassess their skills by watching recorded lessons. Medical students can watch the recorded lessons in a sequence to see their improvement over time. In addition, English teachers can assess medical students' development by showing the recorded lesson to another English teacher, whom they trust, and asking for constructive feedback.

The use of the zoom in learning process, there is a research from Archibald (2019) that reveals the use of zoom in teaching and learning seems to be more convenience by both teacher and learners as they both can be at home or particular suitable place to do the online learning. It is believed that learning process in zoom can practiced that learners to be more confident to talk and ask questions as some learners are sometimes shy to talk and ask question when their classmate are around. Then, Archibald also mentions that zoom can facilitate the learners needs in online learning process as the zoom provides with screen sharing and record options which enable the learners to interact with others and comprehend the material.

The writing learning process with the use of zoom as online platform, in 2015 Carolan and Kyppo found that writing process is not basically about the hand writing with grammatical correctness and words meaningful connection, but also it includes the ability of hand typing on computer keyboard when the situation is online based. Also, it is stated that doing any kind of writing activities with online platform seems to be easier by the learners to type the words and connect the meaning with other words as the learners need no good handwriting on this situation which means all words typing can be read as easier. Further, in online learning with special online platform (zoom) can give chance for fast typing exercising for the learners that will help the learner to know the location of the letter key on keyboard and one day can help them with their future job. In advance, the writing learning activity can be designed in special topic which involves the typing activity from the learners regarding to the task given, for example the topic about auto biography; the learners need to type in Microsoft Words file about their own self, can be started from their name, their interest, their hobbies, their family and their school.

The use of zoom classroom in writing learning process particularly in primary can be new point to be explained because it is indicated that primary students in age of $5-11$ years old will be having some issues in doing their literacy learning class, especially when with 
words choice, grammatical correctness and also words connection in sentenced and paragraphs (Guzacheva, 2020). Moreover, it is stated that online literacy learning kind of hard to be done since the teacher is unable to be face to face with the learners and showing direct evaluation or suggestion right after the learners are having their issues. In this zoom classroom learning at primary class particularly in writing subject, the learners are claimed to be more active to ask during the online session by showing the share screen to the teacher so that they can have direct correction to the questions that they share in share screen (zoom classroom).

The writing process through zoom classroom in primary can be struggling since the writing is also claimed as the hard process to be done by the learners, particularly for the primary learners, therefore it is claimed that the curriculum need to be complete and strong enough to facilitate the online learning process on this writing learning. One of the international curriculum that has been well-known in global education is fieldwork education international curriculum. This fieldwork education is international education institute that has been working on international curriculum for over 1000 schools in all over the world with almost more than 30 years experiences in international curriculum. This fieldwork education creates the connection between international curriculum and clear learning goals by integrating subject knowledge, personal skills and international mindedness. Further, the international curriculum in fieldwork education is analyzing the needs of children in the place of where they are living in and working in. The analysis creates the clear goals of the children that need to be accomplished through learning at school in which the learning is designed specifically to provide the children with knowledge, skills and mind. Then, with the knowledge, skills and also mind which are provided through learning process in this curriculum from fieldwork there are requirements which determine how the children can be succeed in their working world. From this statement it can be underlined that the needs of the children through this international curriculum by fieldwork education not only designing the learning process which based on learning goals, but also providing functional life skills for the children to be used and applied by the children in their social real world to get succeed. Then, in fieldwork international curriculum, there are always living values which are included in order to provide the children with meaningful integrated mind into their living area and their social interaction with others in society and community. Moreover, there is also specific break down about what kind of learning that should be learnt by the children in certain range of ages. Therefore, fieldwork is dividing their international curriculum into three main stages based on the ages and the needs of the children, namely: IEYC (International Early Years Curriculum), IPC (International Primary Curriculum), and also IMYC (International Middle Years Curriculum).

The IPC (International Primary Curriculum) is the curriculum which is designed special for $5-11$ years old children. This IPC is used for almost by 1000 international schools, and has been applied by over 90 countries (includes Indonesia). IPC is a thematic curriculum in which there is specific topic to be discussed per week that has been integrated into a theme of school term. This theme is specified into some particular subtopic per week with clear goals to be achieved by the children as learners and also by the teachers as the provider. Further, IPC is also known as comprehensive curriculum, which means in this IPC there are general and specific knowledge which are believed are those that children needs in the range of $5-11$ years old. The comprehensive terms include specific personal skills, specific knowledge and also international minded that can provide and help the children on this ages to develop their maximum capability and achieve the learning goals. Moreover, regarding to IPC as comprehensive curriculum, this IPC also known as creative curriculum which contains many of unique, fun and outstanding themes, topics and lesson plan to be taught and showed to the children.

The topics in IPC are designed to be integrated into subject goals, namely: Physical education, ICT and computing, Art, Mathematics, Science, writing, History, Geography, Music, and Social study. Those subjects will be integrated into the topics of the theme that has been designed per term. Especially in writing, this IPC provides the children with contextual theme which leads them into practical writing and reading, for examples: making the news, making character descriptions, writing narrative, and making auto biography. The 
contextual theme in literacy of IPC integrates between knowledge, skills and living values, which means in specific that every single learning activity in literacy of IPC includes knowledge to be comprehended, skills to be mastered and practiced and also living values to lead the children to connect with their social community. For example: the theme in IPC for grade 6 is about News. The breakdown of this News theme will be about what do the basic points of information to be gathered when a news is designed, then the children needs to be able to make their own news as based on the point of information that taught before, for example the children can make news about their local foods, their school, about the local game, and also can be about their teacher at school. Further, those aspects then lead the children into living values of respect in which the children can understand and respect the information that get from the local community and local people, and also the children are be able to apply good manner of politeness during gathering the information for their news. Previous study from Nugroho, Kristiyanto and Doewes (2018) which have conducted a research entitled "Implementasi Pendidikan Jasmani dalam International Primary Curriculum". showed that IPC is so dynamic that it might be adjusted in order to achieve the school objectives that have already been designed in accordance to local cultures, student conditions and school conditions.

From all explanations and theories above, it can be stated that this proposed research entitled "AN ANALYSIS OF LESSON PLAN IMPLEMENTATION THROUGH ZOOM IN TEACHING WRITING BASED ON INTERNATIONAL PRIMARY CURRICULUM IN SUNRISE SCHOOL BALI" is embedded mix method since it analyzes how the writing learning process is conducted through online platform (zoom) in International Primary Curriculum (IPC) at Sunrise School Bali which is a private international school which also includes their obstacles and solutions in teaching writing through zoom in Year 6 (Primary class). The researcher that there were some problems found during the writing learning process in Year 6 class during zoom class learning, namely; learners are found to have (1) problem in typing words with grammatical correctness, and (2) connecting words into meaningful paragraph. These two problems can be categorized as the constraints in writing learning activities during the zoom class.

This research was supported by several previous researchs which have similar topic with this research. First, Iskandar and Syarifuddin (2019), have conducted a research entitled "Pembelajaran Keterampilan Berbahasa dengan Media Audio Visual Melalui Zoom Cloud Meeting di Fakultas Tarbiyah lai Qamarul Huda Bagu". The study was about the use of Zoom meeting for learning Alquran. The result showed that Zoom meeting is successful as a solution for learning Alquran during pandemic of Covid 19.

Second, Nugroho, Kristiyanto and Doewes (2018), have conducted a research entitled "Implementasi Pendidikan Jasmani dalam International Primary Curriculum". This study was about identifying the association between and the implementation of Sports Education into International Primary Curriculum (IPC) as one of the international curriculum designs. IPC is a comprehensive, thematic, dynamic and global curriculum. The method of this study was descriptive qualitative. The conclusion showed IPC is so dynamic that it might be adjusted in order to achieve the school objectives that have already been designed in accordance to local cultures, student conditions and school conditions

Dashtestani (2013) explored the attitude of Iranian teacher toward English as foreign language which was implemented by mobile assisted language learning (MALL). The target participant was 168 teachers. Interview was conducted to 55 teachers. As the result, the study showed positive attitude toward Mobile Assisted Language Learning. The teachers argued that, Internet could give wide benefit for language learning and facilitated language teaching and learning process. It would improve communication, interaction, and problemsolving, but the teachers argued that they did not have skill in developing MALL in the classroom. The result of the study may be related to the concept of digital native. Santosa (2017) stated that today's students were different for those who were born before 1990s. The students who were born before 1990s may have different learning style and needs to the students who were born 1990s-2000s.

Al-husain et al (2015) had conducted research about college students' readiness toward ICT and mobile learning. The participant of the study was 317 under graduated 
student who were studying in King Saudi University. Survey design was used to collect the data by employing closed-ended questionnaire. The researchers found that ICT usage and mobile learning usage were very high. The study showed that the students were more involved in using internet from handled devices. In term of gadget ownership, $96 \%$ students owned laptop and $86 \%$ owned Smartphone. Those devices were considered as high level of the technology owner ship rather than iPod, desktop computer, mp3 player, iPod touch, tablet, and e book reader. The researcher predicted that the technology ownership of the students was moving to the mobility. The researchers also explored their perception. $89 \%$ students agreed that technology was easy to access resource, $88 \%$ the students were connected, $86 \%$ stated that working faster and good quality of work by using internet, $56 \%$ strongly agree that the learning will be fun, creative, and authentic. It could be seen that the technology especially mobile phone was strongly applicable and considered the students as a native mobile technology. The researcher implied that mobile phone and social media in academic life should be adopted in the future.

Calabrich (2016) investigated learners' perception toward mobile technology usage for learning English in private school. The total of the participant was 62 students. The demographic data showed that, $87.1 \%$ students had Smartphone and $9.7 \%$ have both Smartphone and tablet. In the research methodology, the learners were given first experience before they share their thought about Mobile Assisted Language Learning. There was no age limit in the research. As the result, the learner gave positive attitudes about incorporative mobile into language learning. The learners argued that using internet from their device giving them benefit about visual scaffolding. Most of students also argued that using mobile phone to perform task made the lesson more realistic. It could be implied that, using of handheld device in learning could increase students' motivation because it personalized the learning, provide global access of information, and easy to use.

So (2016) conducted a study to evaluate mobile instant messaging tools to support teaching and learning. The participant of the study was 61 under graduated students. Pretest and post-test were conducted. The participants were divided into experimental group and control group. WhatsApp was assigned the study. The experimental group was taught and mediated by bite size multimedia material and WhatsApp facilitated teacher-learner interaction outside school hours. For the control group, the learner only used WhatsApp in academic. As the result, the experimental group performed better and showed positive perception and acceptance through questionnaire. Thus, it could be implied that various applications could be installed on mobile devices to support mobile learning needs and giving reference as tools to support learning content in development of mobile learning.

Marchewka and Kostiwa(2007) conducted study to describe students' perception in term of applying UTAUT toward course management software. The researcher added selfefficacy, attitudes and anxiety on the model. The course management software in the study was called blackboard. It is used to support the development of problem solving and critical thinking. The participants of the study were under graduated and graduated business school at a large Midwestern university in United States. The total participants were 132 participants. In data analysis, the researcher used correlation and descriptive analysis. Correlation analysis was used to measure the relation among the variable in the model. Descriptive analysis was used to give understanding about students' perception toward the dimension. As the result, Age and gender did not find significant differences toward the variables. The participant had positive perception toward course management software in term of performance expectancy and effort expectancy, but it seems moderated in term of social influence.

Bogart and Wichadee (2015) conducted study to explore students' intention toward the use of LINE Apps for academic purposes such as submitting homework, following instructions, and downloading learning materials. The total of participant of the study was 144 students. The participants enrolled learning activity based on LINE apps. The questionnaire was developed based on TAM (Technology Acceptance Model). As the result, there were positive relationship between perceived usefulness and attitudes toward the usage of the apps. Thus it could be concluded that students had intention toward the usefulness of LINE apps. 
Then, Kaur et.al in 2020 have conducted a study entitled "Rethinking English Language Teaching Through Telegram, Whatsapp, Zoom, and Zoom". This study was investigating ESL teachers' strategies on English Language teaching during the movement control order at selected secondary schools in Malaysia. This study was a descriptive case-study design. The findings from the study showed that the ESL teachers have resorted to Telegram, WhatsApp, Zoom and Zoom as to engage the students in the learning process during the movement control order. Teachers used various Apps such as Quizziz, Padlet and Kahoot to conduct online assessment after the teaching process ends. The findings indicate that the teachers have good mastery and knowledge of planning, executing, interacting, engaging and assessing students based on the apps used for instruction.

Next, Rahayu (2020), has conducted a research entitled "Synchronous Zoom Web Conference System: An Exploratory Study on Students' E-Learning Experience”. This research was exploring students' experience and what they perceive from the implementation of synchronous e-learning through zoom conference system. Using exploratory sequential design, the data were collected from 62 students taking an English subject in a university in Indonesia. Classroom observations and a set of a questionnaire by a five-point Likert scale were used to collect the data. The result showed positive answers from all three factors. The students agreed that they could communicate at ease before the lesson starts, question and answer during the study process, and work collaboratively through the breakout rooms.

\section{RESEARCH METHOD}

The research was focused on EFL teachers' instructional preparation, implementation, and constraints as found in using Zoom platform for teaching writing in the Elementary School. The data on EFL teachers' instructional preparation and implementation were analyzed quantitatively. Were collected and analyzed qualitatively. Creswell (2012) refers such research design as an embedded Mixed Method. The research subjects or participants in classroom research are 3 primary teachers in International School and 1 class of year 6 students in International School. This research formulates three different questions in which the research objects are the instructional preparation, implementation and constraints found by both the EFL learners and teachers in writing through Zoom platform in the International School. Instrumen Penilaian Persiapan Pembelajaran Undiksha 2020 or Undiksha 2020 Learning Preparation Assessment Instrument, was used to evaluate teaching experience in schools. The reason of using Instrumen Penilaian Persiapan Pembelajaran Undiksha 2020 is because this instruments cover all components which are needed to plan in IPC such as learning goal, learninh outcome, tasks, activities and assessment.

\section{FINDINGS AND DISCUSSION}

Preparing lesson plans for Year 6 Primary through Zoom were measured by eight aspects, namely 1) relation of learning indicators with basic competency, 2) relation of learning materials, learning indicators with basic competency, 3) relation learning methods or techniques with learning materials, 4) learning indicators with basic competency, 5) relation of learning procedures or steps in EFL, 6) relation of evaluation and learning indicators, 7) relation of evaluation instruments and techniques with learning indicators, 7) relation of Information Technology to EFL, and 8) using Information Technology, especially Zoom platform in EFL. The lesson plans prepared by the two different teachers were evaluated by two independent evaluators in order to ensure reliability and validity of measurement. Data on the teachers' ability in preparing lesson plans for EFL though Zoom in the Year 6 Primary are shown in the following tables.

Table 1. Selected Descriptive Statistics of Teachers' Ability in Preparing Lesson Plans

\begin{tabular}{|c|c|c|c|c|c|c|}
\hline \multirow{2}{*}{$\begin{array}{l}\text { Range } \\
\text { Statistic }\end{array}$} & \multirow{2}{*}{$\begin{array}{l}\text { Minimum } \\
\text { Statistic }\end{array}$} & \multirow{2}{*}{$\begin{array}{l}\text { Maximum } \\
\text { Statistic }\end{array}$} & \multicolumn{2}{|c|}{ Mean } & \multirow{2}{*}{$\begin{array}{l}\text { Std. Deviation } \\
\text { Statistic }\end{array}$} & \multirow{2}{*}{$\begin{array}{l}\text { Variance } \\
\text { Statistic }\end{array}$} \\
\hline & & & Statistic & Std. Error & & \\
\hline 1.00 & 3.00 & 4.00 & 3.19 & 0.04 & 0.40 & 0.16 \\
\hline
\end{tabular}

Source: Data analysis of December 2020 SPSS Version 25 
Based on the data in table 1, the teachers' ability mean scores in preparing lesson plan were categorized, they are all in high category (mean \pm 1 standard deviation or $3.19 \pm 0.40$ ). It shows that EFL teachers in terms of preparation wereable to open the class by explaining learning goals, reviewing previous materials as an apperception, andrelating preceding and following learning materials. In terms of learning material, the teachers were able to relate learning materials with basic competency, presents learning materials to achieve basic competency, with sufficient learning materials for respective competency. In terms of learning procedure, the teachers were able to proceed the learning with observation and questions, then continued to exploration, and association. Then, Zoom is chosen as learning media to implement learning process, relate with basic competency, and support learning contents. In terms of utilization, Zoom is utilized to implement learning process, relate with basic competency, and support learning contents. Then, teachers were able to manage the class by deciplining learning,implementing class procedure, andorganizing learning activities in order. In this situation, the teachers gave instruction to the students to keep the class conducive so every students in the online class can learn writing in a comfortable situation. The teacher asked the students to turn on the video while learning writing through Zoom so the teachers can check the behaviour of the students in online class. Then, the teachers were able to use fluent oral and written language,with correct grammar, and appropriate usage. In terms of gesture, the teachers were able to explainlearning material' concepts, contents, and goals using proper gestures. Then, the teachers were able to close the class by wrapping-up learning,summarizing learning outputs, andproviding remedial and enrichment programs.

In terms of implementation, implementing lesson plans for writing through Zoom were measured by nine aspects, namely, 1) openingclass, 2) mastering learning materials, 3) implementing scientific approach, 4) selecting appropriate learning media for writing, 5) utilizing the already selected learning media in writing, 6) managing classroom for writing, 7) using oral as well as written English in writing, 8) showing appropriate gestures in EFL, and 9) implementing good technique in EFL through Zoom platform. Data on the teachers' ability in implementing lesson plans for EFL through Zoom in the Year 6 Primary are shown in the following tables.

Table 2. Selected Descriptive Statistics of Teachers' Ability in Implementing Lesson Plans

\begin{tabular}{|c|c|c|c|c|c|c|}
\hline \multirow{3}{*}{$\begin{array}{l}\text { Range } \\
\text { Statistic }\end{array}$} & \multirow[b]{2}{*}{ Minimum } & \multirow[b]{2}{*}{ Maximum } & \multicolumn{2}{|c|}{ Mean } & \multirow{2}{*}{$\begin{array}{c}\text { Std. } \\
\text { Deviation }\end{array}$} & \multirow[b]{2}{*}{ Variance } \\
\hline & & & & Std. & & \\
\hline & Statistic & Statistic & Statistic & Error & Statistic & Statistic \\
\hline 1.00 & 3.00 & 4.00 & 3.25 & 0.04 & 0.44 & 0.19 \\
\hline
\end{tabular}

Source: Data analysis of December 2020 SPSS Version 25.

Based on the data in table 2, the teachers' ability mean scores in implementing lesson plan were categorized as high category (mean \pm 1 standard deviation or $3.25 \pm 0.44$ ). It shows the teachers were able to open the class by explaining learning goals, reviewing previous materials as an apperception, and relating preceding and following learning materials. In terms of learning material, the teachers were able to relate learning materials with basic competency, presents learning materials to achieve basic competency, with sufficient learning materials for respective competency. In terms of learning procedure, the teachers were able to proceed the learning with observation and questions, then continued to exploration, and association. Then, Zoom is chosen as learning medium to implement learning process, relate with basic competency, and support learning contents. In terms of utilization, Zoom is utilized to implement learning process, relate with basic competency, and support learning contents. Then, teachers were able to manage the class, implementing class procedure, and organizing learning activities in order to be able to use fluent oral and written language, with correct grammar, and appropriate usage. In terms of gesture, the teachers were able to explain learning material' which include the concepts, contents, and using proper vocabulary. Then, the teachers were able to close the class by wrapping-up learning, summarizing learning outputs, and providing remedial and enrichment programs. 
Then, constraints or difficulties found by teachers in preparing lesson plans for writing through Zoom in the Year 6 Primary School Denpasar were difficulty in relating learning indicators to basic competency. It was found that the learning materials were not closely relevant to the basic competency and learning indicators. It happened because of the switch from face to face learning to online learning as the results of the covid-19 pandemic. The teacher seemed to struggle to make an adaptation to this situation. They also had problems with the learning resources that they have in the school. In terms of selecting the learning methods, the teacher were also reluctant to choose the methods or techniques that support the achievement of the basic competency as well as learning indicators. This is related to the availability of the learning materials that can encourage students stay focused during the online instructions. The teacher was used to face to face learning, however the abrupt change in the mode of teaching, the teacher needs to be innovative in developing a new strategy for online class. In terms of learning steps, learning steps are not fully maximize communication. It is happened because the zoom limitation is 40 hours and the teachers need to teach many students with different internet connection. It seemed to be a common practice that the teachers just make it in the form of representative presentation in communication phase. In terms of learning evaluation, the learning evaluation is not consistent with efficiency in terms of time, cost and energy and the learning assessmentis not evaluate learning process and outcome. In terms of selection of Zoom as the learning medium, Zoom was not selected based on the learning efficiency and it is not utilized in accordance to learning outcome.

Teachers in Year 6 Primary School Denpasar also found difficulty in implementing the lesson plans for writing through Zoom. In terms of motivating the students, It is hard to motivate some students for following learning materials and the upcoming learning. Then, It is hard for the teachers to relate learning materials with authentic, contextual, and varied learning materials. In terms of learning steps, it is difficult for teachers to decide on strategies the learning with communication. In terms of using Zoom to implement lesson plan, It is hard to utilize zoom for all students because they have different levels of knowlege, and it is difficult to handle defiant behaviour in Zoom. Besides, it is hard for teachers to give a proper gesture to the students via Zoom. In terms of using oral and written language, It is hard to be comprehensive to learners. This present study isin line with Dashtestani (2014)who has conducted a research which explores Iranian English as foreign language (EFL) teachers' perceptions on the implementation of online EFL instruction in which the result showed that the implementation of online EFL instruction in Iran is challenging due to a number of perceived impediments and obstacles. The most considerable perceived challenges to the implementation of online EFL instruction comprise lack of online facilities and resources, lack of interaction in online instruction, cultural resistances to online instruction and teachers' limited knowledge of online instruction. In this study, most of them are not able to manage computers well, or even could not operate basic programs such as Microsoft Word and Power Point let alone Google Classroom. Time management is a difficult task for EFL teachers and students as on-line learning require a lot of time and intensive work. Selfmotivation on e-learning is an essential requirement; however, many EFL teachers and students lack it. In a contrary, this study is different to previous study from Calabrich (2016) which investigated learners' perception toward mobile technology usage for learning English in private school in which the learner gave positive attitudes about corporative mobile into language learning. The learners argued that using internet from their device giving them benefit about visual scaffolding and most of students also argued that using mobile phone to perform task made the lesson more realistic which could be implied that, using of handheld device in learning could increase students' motivation because it personalized the learning, provide global access of information, and easy to use.

\section{CONCLUSION AND SUGGESTIONS}

The teachers' ability mean scores in preparing lesson plan were categorized, they are all in high category (mean \pm 1 standard deviation or $3.25 \pm 0.44$ ) and the teachers are able to open the class, relate learning materials with basic competency, presents learning materials to achieve basic competency, with sufficient learning materials for respective competency, 
proceed the learning with observation and questions, then continued to exploration, and association, manage the class by deciplining learning, implementing class procedure, and organizing learning activities in order, use fluent oral and written language, with correct grammar, and appropriate usage. In terms of gesture, the teachers were able to explain learning material' concepts, contents, and goals using proper gestures and able to close the class by wrapping-up learning, summarizing learning outputs, and providing remedial and enrichment programs.

The teachers' ability mean scores in implementing lesson plan were categorized as high category (mean \pm 1 standard deviation or $3.25 \pm 0.44$ ) in which the teachers were able to open the class relate learning materials with basic competency, presents learning materials to achieve basic competency, with sufficient learning materials for respective competency, proceed the learning with observation and questions, then continued to exploration, and association, utilize Zoom to implement learning process, relate with basic competency, and support learning contents, manage the class by disciplining learning, implementing class procedure, and organizing learning activities in order, use fluent oral and written language, with correct grammar, and appropriate usage able to explain learning material' concepts, contents, and goals using proper gestures and close the class by wrapping-up learning, summarizing learning outputs, and providing remedial and enrichment programs.

In terms of the constraints in preparing lesson plan, the teachers were difficult in relating learning indicators to basic competency. Then, learning materials, the learning materials are not sufficient to the basic competency and learning indicators. In terms of selecting learning methods, the selection of learning methods or techniques are not based on basic competency as well as learning indicators. In terms of learning steps, learning steps are not completed with communication. In terms of learning evaluation, the learning evaluation is not consistent with efficiency in terms of time, cost and energy and the learning assessment is not evaluate learning process and outcome. In terms of selection of Zoom as learning media, Zoom is not selected based on learning efficiency and it is not utilized in accordance to learning outcome.

In terms of constraints in implementing lesson plan, the teachers were difficult in motivating some students for following learning materials and the upcoming learning, relating learning materials with authentic, contextual, and varied learning materials. In terms of learning steps, proceeding learning with communication, utilizing zoom for all students because they have different level of knowledge and it is difficult to handle defiant behaviour in Zoom, giving a proper gesture to the students via Zoom and being comprehensive to learners.

\section{REFERENCES}

Al-husain, D., Hammo, B. H., \& Arabia, S. (2015). eT, 4(1), 48-55.

Barton, D. C. (2020). Impacts of the COVID-19 pandemic on field instruction and remote teaching alternatives: Results from a survey of instructors. Ecology and Evolution, 10(22), 12499-12507. https://doi.org/10.1002/ece3.6628

Bogart, W. Van De, \& Wichadee, S. (2015). Exploring Students 'Intention to Use LINE for Academic Purposes Based on Technology Acceptance Model, 16(3), 65-85.

Calabrich, S. L. (2016). Learners 'Perceptions of the Use of Mobile Technology in a TaskBased Language Teaching Experience, 9(12), 120-136. http://doi.org/10.5539/ies.v9n12p120

Creswell. (2012). Educational Research Planning, Conducting and Evaluating Quantitative and Qualitative Research. United States of America: PEARSON

Dashtestani, R. (2013). language learning ( MALL ) in an EFL context : Iranian EFL teachers ' perspectives on challenges and a ff ordances, 9(2), 149-168.

Ferri, F., Grifoni, P., \& Guzzo, T. (2020). Online Learning and Emergency Remote Teaching: Opportunities and Challenges in Emergency Situations. Societies, 10(4), 86. https://doi.org/10.3390/soc10040086 
Guzacheva, N. O. (2020). ZOOM TECHNOLOGY AS AN EFFECTIVE TOOL FOR DISTANCE LEARNING. 457-460.

Iskandar, R. \& S. (2019). PEMBELAJARAN KETERAMPILAN BERBAHASA DENGAN MEDIA AUDIO VISUAL MELALUI ZOOM CLOUD MEETING DI FAKULTAS TARBIYAH IAI QAMARUL HUDA BAGU. Journal of Chemical Information and Modeling, 53(9), 1689-1699.

Kaur, C., Singh, S , U., Idris, S., Singh, T., Singh, M., ... Idris, S. (2020). Rethinking English Language Teaching Through Telegram, WhatsApp, Google.11(11),45-54

Marchewka, J. T., \&Kostiwa, K. (2007). An Application of the UTAUT Model for Understanding Student Perceptions Using Course Management Software, 7(2), 93104.

Nugroho, K. A., Kristiyanto, A., \& Doewes, M. (2018). Implementasi pendidikan jasmani dalam international primary curriculum. Jurnal Keolahragaan, 6(2), 110-119. https://doi.org/10.21831/jk.v0i0.21336

Rahayu, D. (2020). Synchronous Zoom Web Conference System: An Exploratory Study on Students' E-Learning Experience. Journal of ELT Research, 5(1), 68-79. https://doi.org/10.22236/JER

Reimers, F., Schleicher, A., Saavedra, J., \& Tuominen, S. (2020). Supporting the continuation of teaching and learning during the COVID-19 pandemic. Oecd, 1-38.

Reynolds, J. A., Cai, V., Choi, J., Faller, S., Hu, M., Kozhumam, A., ... Vohra, A. (2020). Teaching during a pandemic: Using high-impact writing assignments to balance rigor, engagement, flexibility, and workload. Ecology and Evolution, 10(22), 12573-12580. https://doi.org/10.1002/ece3.6776

Sugianto, A. (2020). Applying a Lesson Plan for a Digital Classroom: Challenges and Benefits. 02(02), 21-33.

Sulfasyah, Bahri, A., \& Saleh, S. F. (2018). Writing lessons in grade 1 Indonesian thematic textbooks: A content analysis. Indonesian Journal of Applied Linguistics, 7(3), 495-503. https://doi.org/10.17509/ijal.v7i3.9789

Yinling, C. (2016). Teaching writing. Teaching Language Skills, (August 2016), 113-134. https://doi.org/10.1007/978-3-319-38834-2 